\title{
PSYCHOTHERAPEUTIC CORRECTION SYSTEM OF SOMATOGENIC DEPRESSIVE DISORDERS IN PA- TIENTS WITH CEREBRAL STROKE
}

\author{
Kharkiv National Medical University, Kharkiv, Ukraine 1. \\ GI“Institute of Neurology, Psychiatry and Narcology of the NAMS of Ukraine”, Kharkiv, Ukraine 2.
}

\begin{abstract}
The article shows the results of examination of 60 patients with cerebral stroke. The study implied the assessment of the development of somatogenic depressive disorders for one year. Acute phase of cerebral stroke was characterized by various disorders of consciousness which were further accompanied by cognitive impairments, and after disorders of consciousness disappeared patients developed various psycho-emotional disorders, predominantly somatogenic depression and anxiety. The proposed psychotherapeutic correction system has allowed to reduce the frequency and severity of this disorders and to improve quality of life and social functioning of post-stroke patients.
\end{abstract}

KeyWords: Somatogenic depression, anxiety, psychotherapy, cerebral stroke.

\section{INTRODUCTION}

Today, there are no doubts that "the era of neurotic disorders", the main mental group of diseases in the twentieth century, comes to an end, and the beginning of the twenty-first century is replaced by "Somatogenic depressive disorders era". Post-stroke depressive disorders usually develop within 3-24 months after the stroke and are defined as "mood disorders caused by cerebrovascular diseases associated with the symptoms of depression, anxiety and hypochondria, with the presence of episodes such as major depressive or mixed". The majority of cerebral stroke (CS) patients suffered from depressive disorders that complicated the course of treatment, the outcomes of the disease, the recovery and rehabilitation processes [15]. Approximately $10-15 \%$ of patients with depression are prone to suicide attempts $[6,7]$.

\section{Corresponding Author:}

Volodymyr Mykhaylov, MD, MD, PhD, associate professor of the Department of Psychiatry, Narcology and Medical Psychology Kharkiv National Medical University, Ukraine. E-mail: MykhaylovV@yandex.ru
Headache is the initial symptom of the majority of vascular diseases of the brain; hence, diagnosis of the causes of headache becomes essential for preventing the development of vascular disease [6, 7]. The available published data contain no results of a comprehensive study of the arterial and venous hemodynamics, cerebrovascular reactivity (CVR) in patients with $\mathrm{CH}$. All the mentioned above determines the timeliness of our research.

\section{PURPOSES, SUBJECTS and METHODS:}

\subsection{Purpose}

to assess the development of somatogenic depressive disorders in CS patients to elaborate a system of psychotherapeutic support and correction of such disorders.

\subsection{Subjects \& Methods}

The study involved 60 patients with ischemic cerebral stroke. The main group included 70\% (42) male and 30\% (18) female patients. Most of them, $43.3 \%$ (26 patients) were aged $56-65$ years, $41.7 \%$ ( 25 patients) were aged 46 - 
Table 1.

55 years, 15\% (9 patients) were aged $36-45$ years. The average age of the patients was $53.3 \pm 5.5$ years. Among them, middle cerebral arteries were involved in the pathological process in 42 cases $(70 \%)$, and vertebra basilar basin in 18 cases $(30 \%)$. The number of patients with ischemic CS in the left or in the right middle cerebral artery was equal and amounted for 21 patients (35\%).

The patients were examined in 4 stages: stage 1 within 28 days after CS (acute phase), stage 2 - 3 months after the event, stage 3 - 6 months after the event (recovery period), Stage 4 - 1 year after the event (period of consequences). Throughout the period of the survey the patients underwent psychotherapeutic correction and psychological support secondary to basic therapy.

Clinical methods, psycho-diagnostic methods [by 8] (The Modified Rankin, Scale Hamilton scale of depression (HDRS), Beck scale of depression (BDS), Spylberger scale of personal and reactive anxiety, Mini-Mental State Examination (MMSE) and quality of life test [9].

All the data is processed by conventional medical methods of statistical analysis with Microsoft Excel 2010 package, Statistics for Windows 5,0 applications. Frequency of clinical signs presented in absolute values and expressed as a percentage. The findings of a number of psychodiagnostical techniques processed by methods of variation statistics with finding of the arithmetic mean and its error. The validity of the results is determined by Student's criteria (differences were considered significant at $p<0.05$ ). In the analysis of the interrelationship of the results obtained using psychodiagnostical techniques correlation analysis method has been used. Correlation study was conducted to establish the links in quantified indices with.

\section{Conflict of interests}

There is no conflict of interests.

\section{RESULTS AND DISCUSSION}

All the patients during acute stage of CS were found to have various impairments of consciousness (Table 1 ). cerebral stroke

\begin{tabular}{|l|c|c|}
\hline \multirow{2}{*}{$\begin{array}{l}\text { Impairments of } \\
\text { consciousness }\end{array}$} & \multicolumn{2}{|c|}{$\begin{array}{c}\text { Number of patients } \\
\text { pumber of } \\
\text { patients }\end{array}$} \\
\hline Somnolence & 6 & 10.0 \\
\hline Obnobulation & 28 & 46.7 \\
\hline Torpor & 22 & 36.6 \\
\hline Sopor & 4 & 6.7 \\
\hline
\end{tabular}

As shown on Table 1 all the patients had impaired consciousness of different severity. Depth of consciousness correlated with the severity of CS. There was a high representation (in $94 \%$ of cases) of surface forms of impaired consciousness, namely somnolence (10.0\%), obnubilation (47.0\%), lung torpor (37.0\%). Besides, $7 \%$ of patients had sopor, which is a more severe impairment of consciousness.

These conditions were characterized by the preservation of all types of orientation, but with the difficulty of clear awareness due to the increased threshold of perception. Herewith torpor was characterized by a steady state and obnubilation by undulating. The main manifestations of this condition included relative bradikinesis and slow response to external stimuli. Within 1-3 days these syndromes transformed into clear consciousness. Transition to clear consciousness occurred in the following forms:

1) short-term (within 12-24 hours) period of somnolence, the original version of the disturbance of consciousness characterized by increased sleepiness;

2) same as a short-term (12 - 24 hours) period of elevated wakefulness, a condition characterized by a relative acceleration of thinking, agitation, hyperactivity of patients;

3) smooth transition directly into clear consciousness.

Presentation was as follows: headache associated with fluctuations in blood pressure, feeling of heaviness in the
Impairment of consciousness in acute stage of 
head, pain in the eyes, dizziness, unsteadiness during walking, sleep disturbances, noise and ringing in the ears and head, asthenia, cognitive impairment.

Patients with CS in the system of the middle cerebral artery mainly presented with weakness in the contralateral limbs, numbness, and impaired sensitivity in the limbs. Patients with left-hemispheric carotid disorders had speech disorder in the form of motor, sensory and amnestic aphasia. Patients with stroke in the vertebra basilar basin more commonly complained of persistent dizziness, mainly started after changing the position of the body or turning the head, noise and ringing in the head or ears, nausea, difficulty in swallowing, dysarthria, visual disturbances.

Physical examination showed that all the patients had diffuse organic symptoms in combination with focal disorders. Oculomotor disorders were predominant: weakness of convergence, restriction in looking upwards, insufficiency of efferent nerves. Patients were found to have facial muscles asymmetry, nistagmus in extreme derivations, violation of statics and coordination, aphasia, motor aphasia (of varying severity), sensitive tone disorders, decreasing of strength in the extremities (contralateral impairment).

The study identified a group of symptoms: decreasing of corneal reflexes, swelling of the tongue with teeth imprints, soreness of the eyeballs with pressure, which were regarded as indirect signs of liquor hypertension. In addition the patients were found to have reflexes of oral automatism and other pathological signs.

Focal neurological symptoms corresponded to the affected vascular regions, the localization of the ischemic lesion.

Analysis of psychopathology in the examined patients showed a prevalence of symptoms typical for acute diffuse organic and focal cortical lesion of CNS (Table 2).

Acute diffuse organic lesions consisted of violations of all kinds of attention (concentration, volume, shifting). Sensory disorders were very frequent. Focal cortical symptoms included disturbances of higher cortical functions. The most common were various types of aphasia: sensory, motor, amnestic and their combined forms. Amnestic disorders were manifested mainly in the form of fixation amnesia which regressed during the recovery of attention.

The affective sphere was unstable, with rapid changes in the emotional background, emotional lability with excessive insecurity and vulnerability, irritability, uncontrolled emotional reactions, affective flashes, frequent changes of mood, with a predominance of fear and anxiety. Presentation also included general weakness, loss of appetite, fatigue, rapid exhaustion, sleep disorders (sleep process, depth and duration of sleep, daytime sleepiness), suspiciousness, feelings of guilt, tearfulness, diffidence.

Identification of clinical and psychopathological disorders in patients with CS, features of their clinical structure and dynamics allowed us to distinguish leading clinical syndromes and types of patients' attitude to their disease (Table 3).

At the acute stage of CS all the patients predominantly had impairment of consciousness (mostly superficial forms, somnolence, obnubilation, torpor) followed by cognitive disorders. Cognitive impairment was characterized by the deficiency of mnestical, intellectual functions and emotional sphere.

Asthenic syndrome was basic, characterized by fatigue, irritability, general weakness, unstable mood. Pain syndrome was characterized by headaches, pain in the epigastria, cardialgia.

At the second stage of the study (3 months after CS) presentation and the severity of cognitive impairments decreased, giving rise to different psycho-emotional disorders.

Asthenic syndrome remained leading and at the same time the amount of patients with depressive and anxiety syndrome increased to $33.3 \%$ of the patients suffering from depressive syndrome and 16.7 \% from anxiety.

Depressive syndrome was represented by the patients' pessimistic attitude to the environment. 


\section{Representation of psychopathology in patients after cerebral stroke at all the stages of survey}

\begin{tabular}{|c|c|c|c|c|c|c|c|c|}
\hline \multirow{3}{*}{ Symptoms } & \multicolumn{8}{|c|}{ Representation on the survey stage } \\
\hline & \multicolumn{2}{|c|}{1} & \multicolumn{2}{|r|}{2} & \multicolumn{2}{|c|}{3} & \multicolumn{2}{|r|}{4} \\
\hline & № & $\% \pm m \%$ & № & $\% \pm m \%$ & № & $\% \pm \mathrm{m} \%$ & № & $\% \pm \mathrm{m} \%$ \\
\hline Hypersthesia & 14 & $23.3 \pm 0.7$ & 10 & $16.7 \pm 0.3$ & 6 & $10.0 \pm 0.2$ & - & - \\
\hline Hyposthesia & 34 & $56.7 \pm 1.3$ & 20 & $33.3 \pm 0.2^{*}$ & 12 & $20.0 \pm 0.2^{*}$ & 5 & $8.3 \pm 0.1^{*}$ \\
\hline Senestopathia & 14 & $23.3 \pm 0.7$ & 10 & $16.7 \pm 0.3^{*}$ & 6 & $10.0 \pm 0.2$ & 2 & $3.3 \pm 0.1^{*}$ \\
\hline Bradikinesis & 56 & $93.3 \pm 1.7$ & - & - & - & - & - & - \\
\hline Disorientation in time and space & 6 & $10.0 \pm 0.2$ & - & - & - & - & & \\
\hline Disorders in self estimation & - & - & 10 & $16.7 \pm 0.3$ & 12 & $20.0 \pm 0.2$ & 5 & $8.3 \pm 0.1$ \\
\hline \multicolumn{9}{|l|}{ Disorders of speech: } \\
\hline Motor aphasia & 4 & $6.7 \pm 0.1$ & 4 & $6.7 \pm 0.1$ & 2 & $3.3 \pm 0.1$ & 1 & $1.7 \pm 0.1$ \\
\hline Sensor aphasia & 4 & $6.7 \pm 0.1$ & 2 & $3.3 \pm 0.1$ & 2 & $3.3 \pm 0.1$ & 1 & $1.7 \pm 0.1$ \\
\hline Sensor and motor aphasia & 10 & $16.7 \pm 0.3$ & 6 & $10.0 \pm 0.2$ & 6 & $10.0 \pm 0.2$ & 4 & $6.7 \pm 0.1$ \\
\hline Amnestic aphasia & 10 & $16.7 \pm 0.3$ & 8 & $13.3 \pm 0.7$ & 6 & $10.0 \pm 0.2$ & 3 & $5.0 \pm 0.1$ \\
\hline Disorders of attention & 56 & $93.3 \pm 1.7$ & 18 & $30.0 \pm 0.2^{*}$ & 24 & $40.0 \pm 0.4^{*}$ & 12 & $20.0 \pm 0.2^{*}$ \\
\hline Memory disorders & 58 & $96.7 \pm 1.3$ & 14 & $23.3 \pm 0.7^{*}$ & 16 & $26.7 \pm 0.3$ & 9 & $15.0 \pm 0.5^{*}$ \\
\hline Disorders of sleep & 54 & $90.0 \pm 1.6$ & 40 & $66.7 \pm 1.3^{*}$ & 34 & $56.7 \pm 1.3^{*}$ & 16 & $26.7 \pm 0.3^{*}$ \\
\hline Fatigue & 54 & $90.0 \pm 1.7$ & 42 & $70.0 \pm 1.3^{*}$ & 34 & $56.7 \pm 1.3^{*}$ & 34 & $56.7 \pm 1.3$ \\
\hline Irritability & 10 & $16.7 \pm 0.3$ & 20 & $33.3 \pm 0.2^{*}$ & 30 & $50.0 \pm 0.5^{*}$ & 30 & $50.0 \pm 0.5$ \\
\hline Inability to control emotions & 16 & $26.7 \pm 0.3$ & 20 & $33.3 \pm 0.2^{*}$ & 26 & $43.3 \pm 0.7^{*}$ & 26 & $43.3 \pm 0.7$ \\
\hline Instability of mood & 12 & $20.0 \pm 0.2$ & 20 & $33.3 \pm 0.2^{*}$ & 26 & $43.3 \pm 0.7^{*}$ & 26 & $43.3 \pm 0.7$ \\
\hline Apathy & 6 & $10.0 \pm 0.2$ & 18 & $13.3 \pm 0.7$ & 10 & $16.7 \pm 0.3$ & 10 & $16.7 \pm 0.3$ \\
\hline Filling of guilt & 6 & $10.0 \pm 0.2$ & 10 & $16.7 \pm 0.3$ & 6 & $10.0 \pm 0.2$ & 4 & $6.7 \pm 0.1$ \\
\hline Diffidence & 12 & $20.0 \pm 0.2$ & 14 & $23.3 \pm 0.2$ & 18 & $30.0 \pm 0.2^{*}$ & 16 & $26.7 \pm 0.3$ \\
\hline
\end{tabular}

Table 3.

Leading depressive and associated disorders in patients with CS

\begin{tabular}{|c|c|c|c|c|c|c|c|c|}
\hline \multirow{3}{*}{ Syndromes } & \multicolumn{8}{|c|}{ Representation on the survey stage } \\
\hline & \multicolumn{2}{|r|}{1} & \multicolumn{2}{|r|}{2} & \multicolumn{2}{|c|}{3} & \multicolumn{2}{|r|}{4} \\
\hline & № & $\begin{array}{l}\% \pm \\
\mathrm{m} \%\end{array}$ & № & $\begin{array}{l}\% \pm \\
\mathrm{m} \%\end{array}$ & № & $\begin{array}{l}\% \pm \\
\mathrm{m} \%\end{array}$ & № & $\% \pm m \%$ \\
\hline Impairment of consciousness & 60 & $100.0 \pm 1.7$ & - & - & - & - & - & - \\
\hline Pain & 40 & $66.7 \pm 1.3$ & 32 & $53.3 \pm 1.7^{*}$ & 26 & $43.3 \pm 0.7^{*}$ & 20 & $33.3 \pm 0.7^{*}$ \\
\hline Phobic & 6 & $10.0 \pm 0.2$ & 8 & $13.3 \pm 0.7$ & 12 & $20.0 \pm 0.2$ & 10 & $16.7 \pm 0.3$ \\
\hline Asthenic & 40 & $66.7 \pm 1.3$ & 24 & $40.0 \pm 0.4^{*}$ & 12 & $20.0 \pm 0.2^{*}$ & 10 & $16.7 \pm 1.3$ \\
\hline Hypochondriac & 2 & $3.3 \pm 0.1$ & 6 & $10.0 \pm 0.2^{*}$ & 10 & $16.7 \pm 0.3^{*}$ & 8 & $13.3 \pm 0.7$ \\
\hline Depressive & 16 & $26.7 \pm 0.3$ & 20 & $33.3 \pm 0.2^{*}$ & 24 & $40.0 \pm 0.4^{*}$ & 20 & $33.3 \pm 0.2$ \\
\hline Anxiety & 2 & $3.3 \pm 0.1$ & 10 & $16.7 \pm 0.3^{*}$ & 14 & $23.3 \pm 0.7^{*}$ & 14 & $23.3 \pm 0.7$ \\
\hline Hysteroform & - & - & 4 & $6.7 \pm 0.1^{*}$ & 4 & $6.7 \pm 0.1$ & 4 & $6.7 \pm 0.1$ \\
\hline Cognitive disturbances & 50 & $83.3 \pm 1.7$ & 40 & $66.7 \pm 1.3^{*}$ & 48 & $80.0 \pm 1.7^{*}$ & 44 & $73.3 \pm 1.7$ \\
\hline Scornful attitude to the disease & 8 & $13.3 \pm 0.7$ & 6 & $10.0 \pm 0.2$ & 4 & $6.7 \pm 0.1$ & 3 & $5.0 \pm 0.1$ \\
\hline
\end{tabular}


They did not believe in the possibility of recovery, and thought of inevitable physical disability. Typical complaints included sharp decline of strait, loss of desires and aspirations, decreased attention, inability to concentrate on anything: difficulties to read, watch TV, etc. Patients worried about decreased work capacity, inability to perform the previous volume of mental or physical work due to fatigue and weakness. There was a feeling of inner tension, uncertainty, unmotivated anxiety. Sleep disorders were expressed in the form of early awakening, difficulty falling asleep, nighttime awakenings; absence of relaxation and cheerfulness in the morning.

Patients with anxiety syndrome mainly presented with restlessness, feeling of inner tension. At the forefront there were concerns related to physical health. Patients were pessimistic about the possibility of a safe outcome of the disease, did not believe in the possibility of recovery. In addition anxiety strongly associated with other areas of patients' life. Patients were afraid that they could not meet the expectations of others, to cope with the required volume of work. They noted that "all the time they were waiting for some kind of trouble", "something bad might happen."

"Anticipation" situations were especially psychologically painful for these patients. Any slightest delay of relatives caused another bout of anxiety, accompanied by vivid mental images of stroke event. Patients intently listened to conversations of medical staff in the hope of finding out information on their health, at the same time they had a fear of possible further trouble. In such situations they gradually developed emotional instability and irritability.

At the third stage of the study in $80.0 \pm 1.7 \%$ of patients were shown to have cognitive impairments, with the severity of $70.0 \pm 1.7 \%$ which corresponded to mild cognitive impairment. The intensity of psycho-emotional disorders and depressive reactions was increasing. Pain syndrome $(40 \%)$, depressive syndrome $(40.0 \%)$, cognitive impairments $(80.0 \%)$ were predominant. The number of patients with isolated asthenic syndrome decreased to $20.0 \%$. Representation of hysterophorm syndrome at this stage of the research was the same. The incidence of scornful attitude to the disease decreased to $6.7 \%$. Depression and anxiety correlated with the intensity of neurological deficit and its impact on life quality.

At the fourth stage of the research the severity of psycho-emotional disorders and depressive reactions secondary to cognitive impairments remained unchanged, otherwise quantification of major syndromes decreased. So, depressive syndrome was observed in $33.3 \%$ of patients, anxiety syndrome in $23.3 \%$ of patients, hypochondria in $13.3 \%$ of patients, phobic syndrome in $16.7 \%$ of patients, scornful attitude in $5.0 \%$ of patients. At this stage of the study the incidence of cognitive impairment comprised $73.3 \%$. A decrease in cognitive impairments was associated with the reduction in the incidence and severity of psycho-emotional disorders.

The study allowed us to elaborate a multimodal system of psychotherapeutic correction of somatogenic depression, depressive and associated disorders in CS patients (Table 4)

Implementing the system of psychotherapeutic correction, we have selected five stages:

Stage 1 - Diagnostic,

Stage 2 - Adaptational,

Stage 3 - Medical,

Stage 4 - Final

Stage 5 - Psycho-prophylactic.

The diagnostic phase has been directed mainly for the examination of patient's personality: examination of premorbid personality traits; determination of the type of psychogenic reactions; the establishment of the degree of compensation of disturbed functions; psychological testing, definition of suggestibility. This stage involves 5-7 individual sessions during 2 weeks.

The second stage, adaptational, implies therapeutic alliance and is comprised of 2 to 3 individual and 2-3 group sessions during 2 weeks. The main tasks of the stage include psychological, emotional contact with the patient; formation of trust to the psychotherapist, adequate and positive attitude to the psychotherapeutic process. 
Multimodal based system of psychotherapeutic correction of somatogenic depression and associated disorders in CS patients.

\begin{tabular}{|c|c|c|c|c|}
\hline Stages & AIM & $\begin{array}{l}\text { Orientation of } \\
\text { psychotherapy }\end{array}$ & $\begin{array}{l}\text { Methods of } \\
\text { psychotherapy }\end{array}$ & $\begin{array}{l}\text { The numbers and forms of } \\
\text { sessions }\end{array}$ \\
\hline Diagnostical & $\begin{array}{l}\text { Examination of the patients } \\
\text { personality }\end{array}$ & Diagnostic & $\begin{array}{l}\text { Personal - orientated, } \\
\text { rational } \\
\text { CBT }\end{array}$ & 5-7 sessions during 2 weeks \\
\hline Adapta-tional & $\begin{array}{l}\text { Setting psychological, } \\
\text { emotional contact with the } \\
\text { patient; Trust formation to } \\
\text { the doctor; Adequate } \\
\text { treatment, positive attitude } \\
\text { to psycho-therapeutic } \\
\text { process }\end{array}$ & $\begin{array}{l}\text { Mostly } \\
\text { symptomatical, } \\
\text { Partially } \\
\text { pathogenic }\end{array}$ & $\begin{array}{l}\text { Rational, } \\
\text { Inderect, } \\
\text { CBT }\end{array}$ & $\begin{array}{l}2-3 \text { individual and 2-3 group } \\
\text { sessions } \\
\text { During } 2 \text { weeks }\end{array}$ \\
\hline Medical & $\begin{array}{l}\text { Achievement of positive } \\
\text { dynamics of the patient's } \\
\text { emotional state, learning } \\
\text { and transformation personal } \\
\text { reactions of the patient, his } \\
\text { relations system, scale } \\
\text { experience of illness and its } \\
\text { social significance, } \\
\text { correction of psycho- } \\
\text { emotional disorders }\end{array}$ & $\begin{array}{l}\text { Mostly } \\
\text { pathogenic, } \\
\text { Partially } \\
\text { symptomatic }\end{array}$ & $\begin{array}{l}\text { Hypnosuggestive, } \\
\text { cognitive training, AT, } \\
\text { CBT }\end{array}$ & $\begin{array}{l}\text { 5-6 individual and 8-12 group } \\
\text { sessions } \\
\text { During } 9 \text { weeks }\end{array}$ \\
\hline Final & $\begin{array}{l}\text { Consolidating process of } \\
\text { therapeutic results, skills of } \\
\text { psychological self- } \\
\text { regulation, correction of the } \\
\text { system of life goals, values, } \\
\text { attitude to the disease }\end{array}$ & $\begin{array}{l}\text { Mostly } \\
\text { preventive, } \\
\text { Partially } \\
\text { pathogenic }\end{array}$ & $\begin{array}{l}\text { AT, rational, personal } \\
\text { - orientated, self - } \\
\text { hypnosuggestive, } \\
\text { cognitive training, } \\
\text { CBT }\end{array}$ & $\begin{array}{l}\text { 3-5 individual and 6-7 group } \\
\text { sessions } \\
\text { During } 8 \text { weeks }\end{array}$ \\
\hline $\begin{array}{l}\text { Psycho- } \\
\text { preventive }\end{array}$ & $\begin{array}{l}\text { Consolidating therapeutic } \\
\text { process }\end{array}$ & $\begin{array}{l}\text { Mostly } \\
\text { preventive, } \\
\text { Partially } \\
\text { pathogenic }\end{array}$ & $\begin{array}{l}\text { AT, rational, personal } \\
\text { - orientated, } \\
\text { cognitive training, } \\
\text { CBT }\end{array}$ & $\begin{array}{l}\text { 6-12 individual and 6-12 group } \\
\text { sessions } \\
\text { During } 6 \text { month }\end{array}$ \\
\hline
\end{tabular}


This phase involves important analysis of presentation, the severity of psycho-emotional disorders and cognitive deficits. At this stage it is necessary to establish psychological contact between the patient and the physician-therapist (the best type of relationship is the partnership principle).

The third stage, medical or main, consists of 5-6 individual and 8-12 group sessions during nine weeks. The main tasks of the stage are: the achievement of positive dynamics in the emotional condition of the patient, the study and the restructuring of personal reactions of the patients to the disease, their system of relations, understanding of the disease and its social significance. The main directions of psychotherapeutic correction of psycho-emotional disorders of patients included decrease in fear, reduction of anxiety levels as well as levels of depression, hypochondria, asthenia, normalization of mental status, correction of cognitive deficits, cupping clinical manifestations of physical illness.

The fourth stage, the final, includes 3-5 individual and 6-7 group sessions during eight weeks. The main objectives of the phase are to achieve consolidation of therapeutic outcomes, psychotherapeutic skills of self-control, correction of the system of life goals, values, attitudes to the disease, personal ego and the environment.

The fifth stage is psychoprophylaxis. Its duration is 6 months. At this stage patients get psychotherapeutic support. Patients visit their therapist 1-2 times a month. They undergo 6-12 group psychotherapy sessions, 6-12 individual sessions if necessary. The main aim of this stage is to prevent a recurrence of psycho-emotional disorders.

\section{CONCLUSIONS}

The proposed system demonstrated a significant improvement in $77 \%$ of CS patients, it allowed to decrease frequency and severity of somatogenic depressive and anxiety disorders, improve quality of life and social functioning of our patients.

\section{REFERENCES}

1. Hackett, M. L, Yapa, C., Parag, V. Anderson, C.S.
(2005). Frequency of Depression After Stroke: A Systematic Review of Observational Studies. Stroke. 36, 1330-1340.

2. Lincoln, N.B., Flannaghan, T. (2003). Cognitive behavioral psychotherapy for depression following stroke. A randomized control trial. 34, 111-115.

3. Landreville, P., Desrosiers, J., Vincent, C., Verreault, R., Boudreault V. (2009). The role of activity restriction in poststroke depressive symptoms. Rehabil Psychol. 54 (3), 315-322.

4. Kimura, M., Tateno, A., Robinson, R.G. (2003) Treatment of poststroke generalized anxiety disorder comorbid with poststroke depression: merged analysis of nortriptyline trials. Am J Geriat Psychiat. 11, 320-327.

5. Sorbello, D., Dewey, H. M., Churilov, L., Thrift, A. G., Collier, J. M., Donnan, G. Bernhardt, J. (2009) Very early mobilisation and complications in the first 3 months after stroke: further results from phase II of A Very Early Rehabilitation Trial (AVERT). Cerebrovasc Dis, 28 (4), 378383.

6. Carod-Artal, F. J. (2007). Are mood disorders a stroke risk factor? Stroke. 38, 1-3

7. Robinson, R.G. (2006). The clinical neuropsychiatry of stroke.

Robinson R.G. Cognitive, behavioral and emotional disorders following vascular brain injury 317- 354 . Second edition.Great Britain. Cambridge. Cambrige University Press.

8. Mishchenko, T.S., Shestopalova, L.F., Trescinskaya, M.A. (2008). Clinicheskie Schkali I Psychodiagnosticheskie Testi Pri Diagnostike Cerebro-Vaskulyarnix Zabolevaniy [Clinical scale and psychodiagnostic tests for the diagnosis of cerebrovascular disease]. Guidelines. Kharkiv, Ukraine

9. Mezzich J., Cohen N., Liu J., Ruiperez M., Yoon G., Iqabal S., Perez C. (1999). Validization an efficient quality life index. Abstracts XI World Congress Psychiatry «Psychiatry on New Thresholds», Hamburg, Germany, 427428.

Received: 28-Oct. - 2016

Accepted: 20-Dec. - 2016 